\title{
Differences between LAN and Cloud LANs
}

\author{
Babiker Mahialdean Salih ${ }^{1}$, Dr. Hala Aldaw Edreis ${ }^{2}$ \\ ${ }^{1,2}$ Faculty of Engineering, Neelain University, Khartoum -Sudan
}

\begin{abstract}
LANs have historically been designed around blazing speed while WANs have traditionally been designed around money. LANs are designed around speed in large part because LAN speeds increase at a dramatic rate. For example, in the late 1990s it was common for Fortune 500 companies to connect servers to their network using a 10Mbps connection. Today it is becoming common to attach servers to the network using 10Gbps connections. That is a factor of 1,000 increases in speed in just over a decade. in this paper we comparison between Lan And Cloud Lans and We found that the future of networks will become virtual networks, which provide us with money and costs.
\end{abstract}

Keywords: lan, vlan, storage, network, pricing, cloud

\section{Introduction}

As Windows Admins, we have become comfortable with connectivity to the physical network. You can go to any physical server (or desktop PC for that matter) and check the status of the network connection by seeing the "media state", if it's enabled, it's speed, how long it's been up, and what it's connectivity state is, as defined by the Windows OS on that server. We are comfortable with network monitoring tools and agents for physical severs and their physical network connections. So how do things change when a physical server is converted into a virtual machine, run on top of a hypervisor (like vSphere or Hyper-V) and connected to a virtual network? With more and more servers being virtualized (greater than half of all servers in the world now), it's time for Windows Admins to gain comfort with virtual network connections and the virtual infrastructure.

\section{Complexities of Virtual LANs}

As in many other technologies, virtual LANs include a caveat; however, the VLAN caveat is also an advantage: While a VLAN allows hosts to be virtually separated at Layer 2, it doesn't provide a mechanism for communicating between VLANs. To return to our earlier telephone system analogy, sometimes phones in an isolated part of an organization must communicate with other, non-isolated phones. Typically with phone systems this requirement means dialing a specific prefix to call "outside" that isolated part of the phone network; for example, we're told "Dial 9 to get an outside line."

With networks that use VLANs, the only way to communicate with other devices in different VLANs is to bring in a Layer 3 device (a router or Layer 3 switch); this device is configured to allow communications between the devices in different VLANs. This device's Layer 3 (and above) features might be configured to limit the amount and types of traffic allowed between devices. This type of connection can be implemented in a few different ways: using a router that has an interface connected per VLAN on the switch, using a router along with switch trunking capabilities (IEEE 802.1Q), or using a Layer 3-capable switch for multi-layer switching (MLS). We'll address these connection types in more detail in a future article.

\section{Cloud Computing Characteristics}

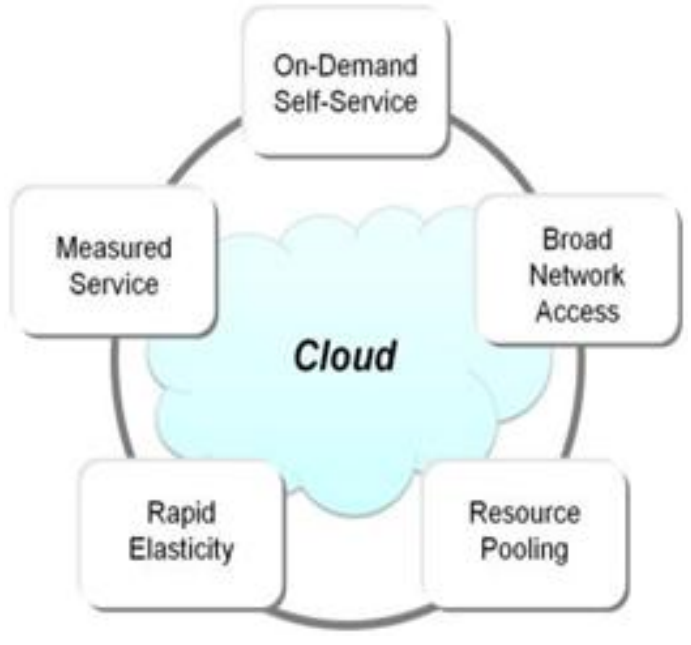

a) On-demand capabilities: A business will secure cloudhosting services through a cloud host provider which could be our usual software vendor. We have access to these services and have the power to change cloud services through an online control panel or directly with the provider. We can add or delete users and change storage networks and software as needed. Typically, we have to pay-for-what-we-use scenario. Terms of subscriptions and payments will vary with each software provider.

b) Broad network access: Our team can access business management solutions using their smart phones, tablets, laptops, and office computers. They can use these devices wherever they are located with a simple online access point. This mobility is particularly attractive for businesses so that during business hours or on off-times, employees can stay on top of projects, contracts, and customers whether they are on the road or in the office. Broad network access includes private clouds that operate within a company's firewall, public clouds, or a hybrid deployment.

c) Resource pooling: The cloud enables your employees to enter and use data within the business management software hosted in the cloud at the same time, from any location, and at any time. This is an attractive feature for multiple business offices and field service or sales teams that are usually outside the office 


\section{International Journal of Science and Research (IJSR) \\ ISSN (Online): 2319-7064 \\ Index Copernicus Value (2013): 6.14 | Impact Factor (2015): 6.391}

d) Rapid elasticity: The cloud is flexible and scalable to suit our immediate business needs. We can quickly and easily add or remove users, software features, and other resources.

e) Measured service: Going back to the affordable nature of the cloud, we only pay for what you use. We and our cloud provider can measure storage levels, processing, bandwidth, and the number of user accounts and we are billed appropriately. The amount of resources that you may use can be monitored and controlled from both our side and cloud provider's side provides an excellent feature of transparency

f) In the past, it was simple.

\section{Data Management}

There was no such thing as network sharing and no such thing as cloud computing. Local storage was the only option. However, as technology continued to advance, IT admins quickly embraced the power of the web. Cloud services such as Dropbox have revolutionized how businesses store information. By saving important files on a non-localized server, employees can access their data from anywhere in the world, as long as they have an internet connection. Unfortunately, unforeseen consequences always follow change - and in this particular instance, data security is the main sacrifice. As a result, corporations must carefully evaluate their options and ask themselves this question, "Which data management method is best - cloud computing, local storage, or network sharing?"

\subsection{Local Storage}

Storing data on a local disk is often the easiest and most straightforward option. As today's desktops can store up to $500 \mathrm{~GB}$ of files, capacity is a non-issue. In fact, even the most rudimentary laptops are fitted with disks of the $160 \mathrm{~GB}$ variety. With so much extra space, it is often forgotten that other alternatives exist.

So why even consider other options? The main allure of a shared network is that important information is protected against physical theft of the device. Luckily, both Windows and Macintosh operating systems feature basic security measures that often breed confidence into concerned IT managers. For example, password protection is a desktop standard and fingerprint validation technology is quickly gaining in popularity. Unfortunately, these safeguards can only do so much, and local storage still contains a number of risks.

The biggest problem with local storage is that a computer virus can easily cripple a hard drive and all of the data that it contains. In fact, a Google study has shown that 8.6 percent of three year-old drives fail. A secondary concern is the theft of an employee's laptop; a risk that is exacerbated when business travel is involved.

\subsection{Cloud Storage}

With the Bring Your Own Device (BYOD) trend as strong as ever, businesses are scrambling to gain control of employee-owned smart phones, laptops, and tablets. IT admins recognize the potential of mobile devices and understand that they can increase productivity if used correctly.

This is where Cloud computing comes in. By hosting data on an online server, employees can access their information from any number of devices. Nevertheless, the ability to access and share files with such ease can be seen as both an advantage and a disadvantage. Foremost, the Cloud has allowed collaborate document writing to become extremely popular. Individuals that are vast distances apart can now work together on a single project; they no longer have to rely on inefficient email communication.

On the other hand, IT departments lose any and all control over online content. Corporations must realize that Cloud services are not immune to data loss; they too are being targeted by skilled hackers. Another drawback is the use of the mobile devices themselves. Even though desktops and laptops are often fitted with password protection and antivirus software, the same cannot be said for smart phones.

\section{Network Sharing}

A centralized network can be considered the happy medium between Cloud and local storage. Similar to a localized drive, this method allows a business to physically backup their data and keep information separate from the internet. In essence, a network share involves a specialized storage computer that is connected to multiple devices.

The big allure of network sharing is that it limits the number of devices that IT has to manage. Rather than running backup software on everyone's desktop, they can focus their efforts on a single platform.

\subsection{Pricing in the cloud}

Pricing in the cloud Pricing is the process of determining what a service provider will receive from an end user in exchange for their services. Weinhardt et al., [9] claimed that cloud computing success in the IT market can be obtained only by developing adequate pricing techniques. The pricing process can be as follows: fixed, in which the customer is charged the same amount all the time; dynamic, in which the price charged changes dynamically; or marketdependent, in which the customer is charged based on the real-time market conditions [17]. Fixed pricing mechanisms include the pay-per-use model, in which the customers pay for the amount they consume of a product or the amount of time they use a certain service. Subscription is another type of fixed pricing, in which the customer pays a fixed amount of money to use the service for longer periods at any convenient time or amount. A list price is another form of fixed pricing, in which a fixed price is found in a catalog or a list. On the other hand, differential or dynamic pricing implies that the price changes dynamically according to the service features, customer characteristics, amount of purchased volumes, or customer preferences. Market dependent pricing, however, depends on the real-time market conditions such as bargaining, auctioning, demand behavior, and yield management. The following are the most pertinent factors that influence pricing in cloud computing

\section{Volume 5 Issue 6, June 2016}

www.ijsr.net 


\section{International Journal of Science and Research (IJSR) \\ ISSN (Online): 2319-7064 \\ Index Copernicus Value (2013): 6.14 | Impact Factor (2015): 6.391}

[10]: 1. Initial costs. This is the amount of money that the service provider spends annually to buy resources. 2 . Lease period. This is the period in which the customer will lease resources from the service provider. Service providers usually offer lower unit prices for longer subscription periods. 3. QoS. This is the set of technologies and techniques offered by the service provider to enhance the user experience in the cloud, such as data privacy and resource availability. The better QoS offered, the higher the price will be.

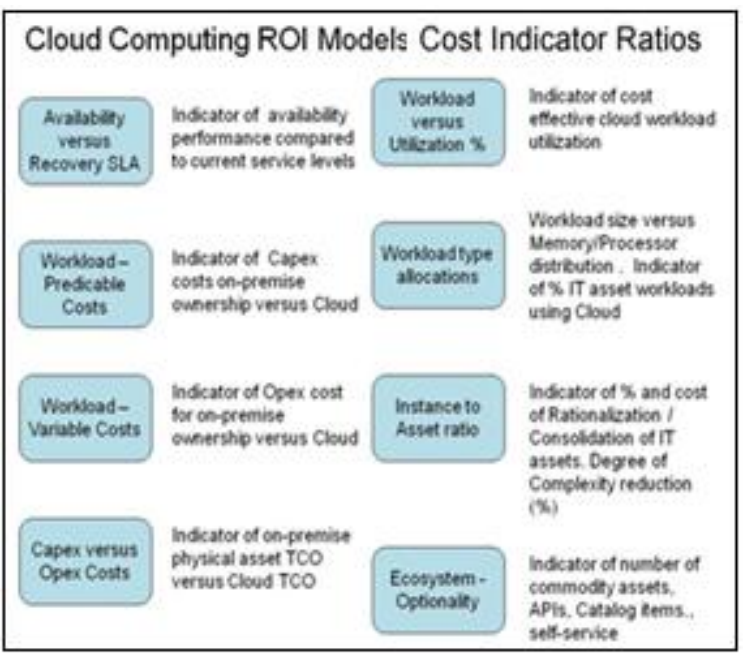

LAN Price Index and Implications Using the results from the previous sections, we calculate that the LAN equipment price index fell at a 17 percent annual rate between 1995 and 2000, about 16 percentage points faster than if the BLS PPI for communications equipment was used. We next used our LAN equipment index to estimate the impact this revised price index would have on real investment in the National
Accounts.LAN equipment is a relatively small portion of private equipment and software spending. Therefore, the effects that this index would have on much larger aggregates will be limited. Nonetheless, we estimate that the real growth rate for certain investment aggregates would be boosted in non-trivial ways. For instance, the real growth of communications equipment would be boosted by an average of 2.4 percentage points a year between 1995 and 2000 by using our index. The comparable figure for total information processing equipment would be about 0.6 percentage points per year. For total non-residential investment, the average real growth rate 21 would be boosted by 0.2 percentage points per year. It is important to note that the results of this paper have already been incorporated into the NIPAs, and that real growth rates for investment in communications equipment and for non-residential investment have been revised upwards as a consequence of them. There is good reason to believe that prices for communications equipment are mismeasured, in part, because of rapid technological change. We examined prices for just one area of communications equipment, LAN equipment. We found that prices fell quite quickly during the later half of the 1990s, although not as quickly as prices of computers. We found that there was a good deal of variation across various LAN categories. This variation appears to be consistent with stories we have heard about the structure of the industry, as well as recent studies on input prices and buyer behavior in this market. We view our research into LAN equipment pricing as one step towards better understanding what actually happened to prices for communications equipment more generally. As shown above, accurate measurement of these prices can have important implications for measurement of investment and productivity growth.

Table 2: Inhibiting factors and the influence of cloud computing

\begin{tabular}{|c|c|c|}
\hline Inhibiting Factor & Inhibiting Effect & Influence of Cloud Computing \\
\hline $\begin{array}{l}\text { Transactional } \\
\text { economies of scale }\end{array}$ & $\begin{array}{l}\text { Fixed costs associated with IT licensing. } \\
\text { customization, and deployment motivate the } \\
\text { partes to increase transaction volume }\end{array}$ & $\begin{array}{l}\text { Reduced fixed costs - capital expenses } \\
\text { are converted to operating expenses, so the } \\
\text { parties have less motivation to trade in high } \\
\text { volume }\end{array}$ \\
\hline $\begin{array}{l}\text { Learning curve } \\
\text { effects }\end{array}$ & $\begin{array}{l}\text { Firms that have already paid the learning } \\
\text { cost associated with IT deployment are } \\
\text { motvated to favor longterm relationships }\end{array}$ & $\begin{array}{l}\text { Increasod standardization - new systems } \\
\text { require lower learning costs and the } \\
\text { leaming curve becomes flatter }\end{array}$ \\
\hline Supplier incentives & $\begin{array}{l}\text { Suppliers make noncontractible, } \\
\text { relationship-speofic investments when their } \\
\text { bargaining power alows them to share the } \\
\text { surplus }\end{array}$ & $\begin{array}{l}\text { Improved adaptability - suppliers are not } \\
\text { required to make noncontractible } \\
\text { investments in adaptabilty, } \\
\text { Introduction of intermediaries - the } \\
\text { coupling of suppliers and customers is } \\
\text { weakened, reducing the significance of } \\
\text { noncontractible investments }\end{array}$ \\
\hline $\begin{array}{l}\text { Information } \\
\text { transparency }\end{array}$ & $\begin{array}{l}\text { Information transparency leads to pricing } \\
\text { pressure and margin erosion }\end{array}$ & $\begin{array}{l}\text { Variation in openness - various } \\
\text { transparency needs can be accommodated }\end{array}$ \\
\hline $\begin{array}{l}\text { Relational } \\
\text { attributes }\end{array}$ & $\begin{array}{l}\text { Relabional attibutes serve as a mechanism } \\
\text { for reducing transaction risks }\end{array}$ & $\begin{array}{l}\text { Reduced switching costs - the reduction } \\
\text { in lock-in provides an aternative } \\
\text { mechanism for safeguarding against } \\
\text { transaction risks }\end{array}$ \\
\hline
\end{tabular}

\section{Conclusion}

As long as your understanding of physical LAN principles was solid before reading this article, you should now have a good idea of what VLANs are and how greatly they affect how a network is designed and implemented. The VLAN's implementation opens a number of doors in terms of the flexibility of a network's design. Virtual networks will be implemented even more frequently in the next few years, as network design changes with newer technologies, making understanding their operation even more important.

In data management with so many options available, it is difficult to pinpoint the perfect data management solution.

\section{Volume 5 Issue 6, June 2016 www.ijsr.net}


The best way to do so is to evaluate each company's needs. If collaboration and file sharing is of utmost importance, then a Cloud service is recommended. If data security is paramount, then a centralized network is probably the best option. Finally, a small business with a low budget is advised to stick with a localized storage system.

\section{References}

[1] Windows Azure Platform, v1.3-Chappell. http://www.microsoft.com/windowsazure/.

[2] Donglai Zhang, Paul Coddington and Andrew Wendelborn," Improving Data Transfer Performance of Web Service Workflows in the Cloud Environment", Int. J. Computational Science and Engineering, Vol. 1, No. 1/1, 2012

[3] Wei Huang, Jiuxing Liu, BulentAbali and Dhabaleswar K. Panda, "A Case for High Performance Computing with Virtual Machines", ICS '06 Proceedings of the 20th annual international conference on supercomputing, pages 125-134

[4] C. Pelletingeas, "Performance Evaluation of Virtualization with Cloud Computing", MSc Advanced Networking, 2010

[5] AlexandruIosup, Simon Ostermann, M. NezihYigitbasi, "Performance Analysis of Cloud Computing Services for Many-Tasks Scientific Computing", IEEE Transaction on parallel and distributed system, VOL. 22, NO. 6, JUNE 2011

[6] MattiasSunding, Maximizing Virtual Machine Performance, vkernel corporation, A Quest Software Company, http://www.vkernel.com

[7] S. Palaniappan Assistant Professor, spalani@psnacet.edu.in, Cloud Computing for Academic Environment, IJCSMC, Vol. 3, Issue. 5, May 2014, pg.8 - 15

[8] GOOGLE Apps, http://www.google.com/apps/business/index.

[9] GOOGLE App Engine, http://code.google.com/appengine.

[10] Apex: Salesforce on-demand programming language and framework, http://developer.force.com/.

[11] Hadoop, http://hadoop.apache.org/.

[12] C. Olston, B. Reed, et al., "Pig latin: a not-so-foreign language for data processing," Proceedings of the 2008 ACM SIGMOD international conference on Management of data. New York, NY, USA: ACM, 2008, pp. 1099-1110.

[13] Enomalism elastic computing infrastructure, http://www.enomaly.com.

[14] Eucalyptus systems, http://eucalyptus.cs.ucsb.edu/.

[15] S. Ghemawat, H. Gobioff, and S.-T. Leung, "The google file system," SIGOPS Oper. Syst. Rev., vol. 37, no. 5, pp.29-43, 2003.

[16] "Amazon simple storage service,"http://aws.amazon.com/s3/.

[17] Yike Guo. Introduction to Cloud Computing. TR. 11, 2009. 